\title{
INVERTEBRADOS MARINOS EOCENOS DE LA PARTE INFERIOR DE LA FORMACIÓN RÍO FOYEL, PROVINCIA DE RÍO NEGRO, ARGENTINA
}

\author{
Jorge O. CHIESA' y Horacio H. CAMACHO' \\ Universidad Nacional de San Luis - Departamento de Geología. Ejército \\ de los Andes 95(). San Luis (570)), Argentina. Correo electrónico: \\ jchiesa@unsl.edu.ar \\ Museo Argentino de Ciencias Naturales "Bernardino Rivadavia". Av. \\ Ángel Gallardo 470, Buenos Aires (1405), Argentina. Correo \\ electrónico: camachoh@muanbe.gov.ar
}

\begin{abstract}
Chiesa, J.O. y Camacho, H.H. 2001. Invertebrados marinos eocenos de la parte inferior de la Formación Río Foyel, Provincia de Río Negro, Argentina. [Eocene marine invertebrates of the lower portion of the Río Foyel Formation, Río Negro Province, Argentina.] Revista Española de Paleontología, 16(2), 299-316. ISSN 02136937.
\end{abstract}

\begin{abstract}
The Rio Foyel Formation was developed during the Eocene-Early Oligocene, in a marine environment extended along the western border of Patagonia and connected with the Pacific Ocean before the main elevation of the Patagonian Andes. It corresponds to a rather deep facies far of the coast, which was located eastward. Its lower Eocene part bears shales with fossiliferous concretions, mainly gastropods and bivalves, beside few brachiopods and echinoderms. In the upper part there are foraminifera, ostracods and microflora of Eocene-Early Oligocene age. 15 species of marine invertebrates collected at the lower part (Eocene) of the Río Foyel Formation are described; 3 of them are news (Fusinus patagoniensis, Neilo biradiata, Panopea zinsmeisteri).
\end{abstract}

Keywords: Invertebrates, systematic, Río Foyel Formation, Eocene, Patagonia, Argentina.

\section{RESUMEN}

La Formación Río Foyel se desarrolló durante el Eoceno-Oligoceno temprano, en un ambiente marino extendido a lo largo del borde occidental de Patagonia y conectado con el Océano Pacífico con anterioridad a la elevación principal de la Cordillera Patagónica. Ella representaría una facies algo profunda y lejana de la costa, la que se hallaba más al oriente. Su tramo inferior (Eoceno) contiene lutitas con concreciones fosilíferas, en su mayoría gasterópodos y bivalvos, además de unos pocos braquiópodos y equinodermos. El tramo superior contiene foraminíferos, ostrácodos y microflora de edad Eoceno tardío-Oligoceno temprano. Se describen 15 especies de invertebrados marinos procedentes de la sección inferior (Eoceno) de la Formación Río Foyel; 3 de ellas son nuevas (Fusinus patagoniensis, Neilo biradiata, Panopea zinsmeisteri).

Palabras clave: Invertebrados, sistemática, Formación Río Foyel, Eoceno, Patagonia, Argentina.

\section{INTRODUCCIÓN}

El Terciario marino de la Patagonia (región austral argentina extendida desde el Estrecho de Magallanes hasta $\operatorname{los} 40^{\circ}-41^{\circ}$ Lat. $S$, aproximadamente) es conocido desde el viaje que realizó Carlos $\mathrm{R}$. Darwin entre los años 1832 - comienzos de 1835 y la publicación de sus observaciones en el año 1846. Hasta los principios del siglo XX fue una creencia generalizada que en la Patagonia, el Terciario marino se hallaba restringido a su litoral atlántico, pero el descubrimiento de la localidad fosilífera del río Foyel mostró que también a lo largo de las estribaciones orientales de la Cordillera Patagónica existían afloramientos marinos de esa edad que además evidenciaban la presencia de transgresiones marinas procedentes del Océano Pacífico, anteriores a la elevación de la cordillera.

Nuevos hallazgos revelaron la extensión e importancia del "Mar Andino" (Ameghino, 1906: 27) durante el Terciario, si bien el conocimiento de la estratigrafía y paleontología de sus depósitos sedimentarios permaneció retrasado con relación al de la región atlánticá. Con el propósito de contribuir a subsanar dicha deficiencia informativa, en los últimos años hemos concentrado nuestras investigaciones en el Terciario marino cordillerano, analizando sus relaciones 


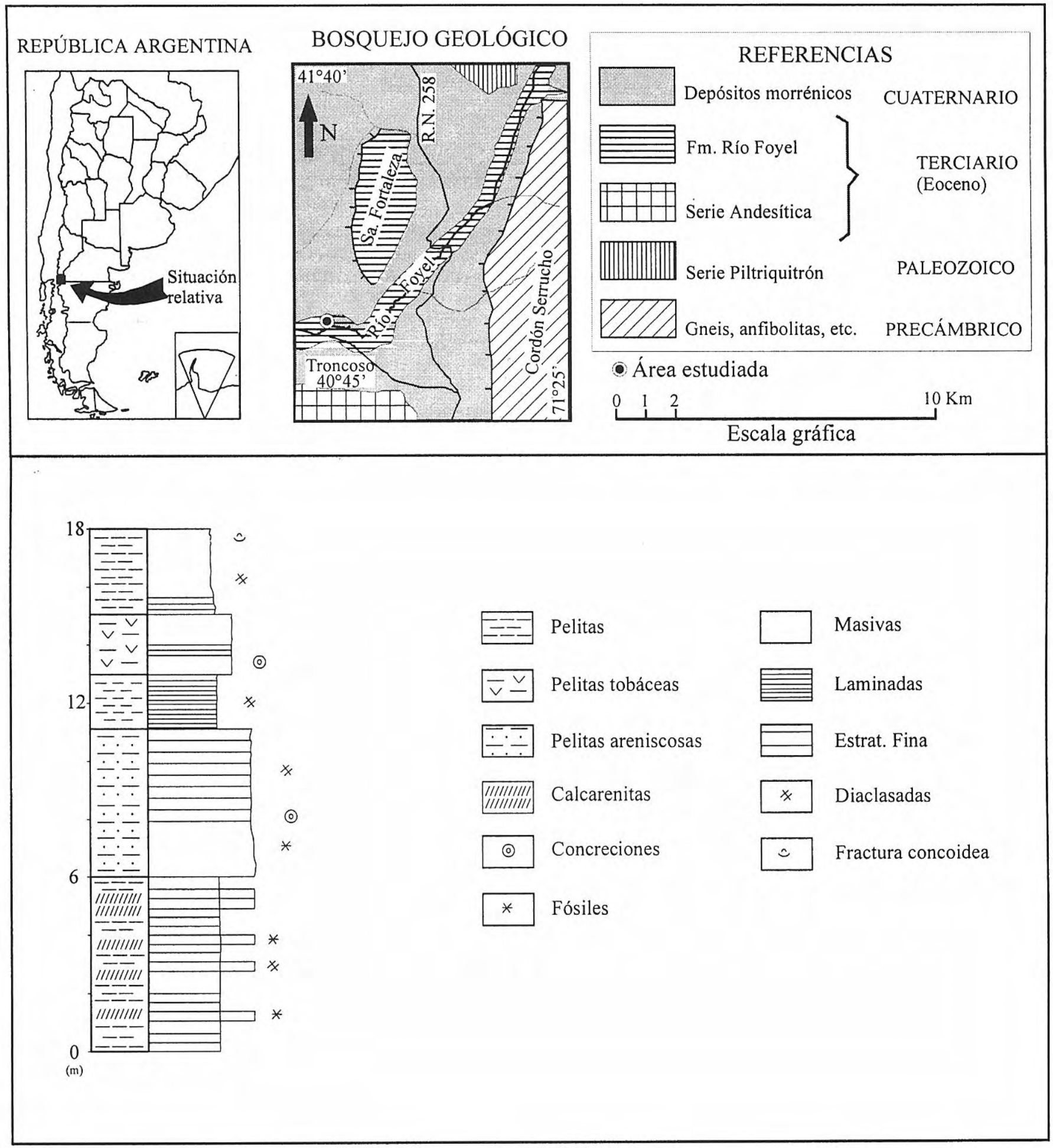

Figura 1. Ubicación geográfica, bosquejo geológico (según González Bonorino, 1944) y perfil estratigráfico del área estudiada con ubicación de los niveles fosilíferos.

Geographic location, geologic sketch (after González. Bonorino, 1944) and stratigraphic profil of the studied area with the ubication of the fossiliferous levels.

estratigráficas y describiendo algunas de sus asociaciones fósiles (Chiesa y Camacho, 1995; Chiesa et al., 1995; Camacho et al., 1998, 2000a, b) agregando, en esta oportunidad, los resultados del estudio de la megafauna de la Formación Río Foyel de la cual, la bibliografía registra una nutrida nómina de especies (Tabla 1), aunque lamentablemente sin proporcionar sus descripciones ni ilustraciones.

Las investigaciones que dieron lugar a esta contribución son parte del Proyecto PIP 4105 CONICET. 


\section{UBICACIÓN GEOGRÁFICA}

La Formación Río Foyel (Pöthe de Baldis, 1984) aflora en el ángulo suroccidental de la Provincia de Río Negro (Fig. 1), sobre las márgenes del río homónimo. Dicho curso de agua es el más importante de la región y tiene sus nacientes en el Nevado Mayor, elevación que contiene la divisoria de aguas (divortium aquarum) entre las cuencas atlántica y pacífica. Desde allí se dirige al suroeste hasta los $41^{\circ} 45^{\prime}$ Lat. S aproximadamente, al sur del Cerro Fortaleza, donde cambia de dirección hacia el noroeste (codo del río Foyel) y desagua en el río Manso, el que después de atravesar el límite internacional argentino-chileno, alcanza el Océano Pacífico.

El perfil que proporcionó los fósiles aquí descritos fue confeccionado sobre la margen derecha del río, donde éste forma un codo, y frente a la Estancia de Troncoso situada unos $25 \mathrm{~km}$ al norte de la localidad El Bolsón (Provincia del Chubut). Desde el nuevo puente sobre la ruta nacional $n^{\circ}$ 258, el afloramiento se halla unos $1.000 \mathrm{~m}$ hacia el oeste.

Una detallada descripción geológica y petrográfica de la región fue realizada por González Bonorino (1944) y en la Fig. 1 se halla un bosquejo geológico del área donde aflora la Fm. Río Foyel.

\section{ANTECEDENTES}

El descubrimiento del yacimiento fosilífero del río Foyel fue hecho por Roth en el año 1898, pero comunicado oficialmente en 1922. Sin embargo, adelantó verbalmente su hallazgo a otros colegas (Roth, 1922: 337), permitiendo a Hauthal efectuar una nueva recolección en dos localidades (a, b), estudiada por Ihering (1904, 1907: 171, 326; 1914: 9, 33, 64).

Entre los primeros estratígrafos en destacar la importancia de este yacimiento se halló Ameghino (1906: $27,145)$ quien, adhiriéndose a la opinión de Roth (seguramente expresada oralmente), consideró que el mismo indicaría la existencia de un antiguo "Mar Andino" originado por brazos extendidos desde el Océano Pacífico.

Corral Foyel fue el nombre original de este yacimiento (Ihering, 1904; Ameghino, 1906; Roth, 1922), posteriormente conocido como "Terciario del Río Foyel" (Feruglio, 1941) o "afloramientos del río Foyel" (González Bonorino, 1944). Otros autores prefirieron destacar la naturaleza petrográfica dominante, como "Esquistos de Foyel" (Roth, 1908; Groeber, 1954), "Lutitas de Río Foyel" (Bertels, 1980, 1993, 1994a, b) y "Lutitas del Río Foyel" (Franchi et al., 1984; Malumián et al., 1984). Pöthe de Baldis (1984: 393, 398) distinguió formalmente esta secuencia como Formación Río Foyel.

Shaw (1939) reconoció, en el río Foyel, el perfil siguiente, desde arriba hacia abajo:

$150 \mathrm{~m}$ - Alternancia de arcillas y tobas arenosas. Restos de plantas. Buenos afloramientos en el cerro Fortaleza.

$100 \mathrm{~m}$ - Andesitas masivas y arcillas andesíticas rojas-verdes. Buenos afloramientos al $\mathrm{N}$ y $\mathrm{O}$ de Los Repollos. $\pm 600 \mathrm{~m}$ - Arcillas negras concrecionarias con fósiles marinos patagonianos en su parte inferior. Buen afloramiento en el valle del río Foyel.

$\pm 150 \mathrm{~m}$ - Andesitas. Buen afloramiento entre los ríos Villegas y Foyel.

- Capas masivas de conglomerados, clastos de granito y diorita hasta de $18 \mathrm{~cm}$ de diámetro. Buen afloramiento cerca del puesto al $\mathrm{S}$ del río Villegas.

$$
\text { -Discordancia- }
$$

-Granito-diorita.

En la parte inferior de las arcillas negras, Shaw halló los moluscos fósiles siguientes, determinados por Feruglio: Panopea nucleus Ihering, 1899, Panopea sp., Cucullaea sp., Venericardia sp., Macoma sp., Glycymeris sp. y Turritella breantiana d'Orbigny, 1847.

Según este perfil, la secuencia marina fosilífera del río Foyel se hallaría intercalada entre rocas andesíticas y tobíferas, criterio seguido por Feruglio $(1941,1949)$ y Groeber (1954), mientras que González Bonorino (1944: 12-19) opinó que si bien las rocas fosilíferas cubrirían, mediante una discordancia erosiva, a las andesitas, superiormente se ubicarían los potentes bancos de calizas y areniscas grisáceas del cerro Fortaleza y finalmente, se hallarían rocas fluviolacustres.

González Bonorino (1944) también proporcionó valiosos datos acerca del diaclasamiento, fracturación, inclinación y mineralogía de las lutitas del río Foyel, cuyos afloramientos más importantes situados frente a la Estancia de Troncoso, serían los que proporcionaron la totalidad de los megafósiles citados en la bibliografía, incluyendo los mencionados por González Bonorino (Tabla 1) y los descritos en este trabajo (Tabla 2).

Siguiendo a Feruglio (1927) y Groeber (1939), González Bonorino (1944) correlacionó estos estratos con el Patagoniano de la costa atlántica y opinó, como Windhausen (1931, II: 311) que representarían la transición entre el Patagoniano y el Navidadense de Chile.

Con respecto al ambiente en el que se depositaron las lutitas del río Foyel, existen opiniones diversas: para Feruglio (1949: 131) correspondería a una cuenca profunda. González Bonorino (1944: 20, 22, 23) consideró que su sedimentación debió efectuarse lejos de la costa. Spalletti (1984) sostuvo que la sedimentación habría tenido lugar en un golfo marino en el que se originaron facies de mar abierto, bajo reducida energía cinética. Mientras que Bertels (1980), basándose en los foraminíferos, expresó que se trataría de un mar restringido que estaba pasando a ser menos profundo. Además, esta autora señaló dos pulsos transgresivos separados por ambientes marinos marginales y optó por una conexión con la Cuenca Austral más bien que con el Océano Pacífico, como fuera sostenido por otros autores (Ameghino, 1906; Roth, 1908; Windhausen, 1931; Groeber, 1954; Feruglio, 1949; Camacho, 1967; Ramos, 1982).

Las primeras menciones de fósiles de Foyel se deben a Ihering $(1904,1907,1914)$ quien determinó ejemplares proporcionados por Hauthal (y no por Roth como suele afirmarse generalmente), procedentes de las localidades a 


\begin{tabular}{|c|c|c|c|c|c|c|c|}
\hline & \multicolumn{2}{|c|}{1} & \multirow[t]{3}{*}{2} & \multirow[t]{3}{*}{3} & \multirow[t]{3}{*}{4} & \multirow[t]{3}{*}{5} & \multirow{3}{*}{ Designación actual } \\
\hline & & & & & & & \\
\hline & a & b & & & & & \\
\hline Terebratella venter Ihering & & $\mathrm{x}$ & & & & & Pachimagas venter \\
\hline Cucullaea $s p$. & & & $\mathrm{x}$ & & & & \\
\hline Pinna cf. tumida Philippi & & & & & & $\mathbf{x}$ & Atrina cf. rioturbienis Griffin \\
\hline Chlamys aff. geminatus (Sowerby) & & & & & & $\mathrm{X}$ & Zygochlamys aff. geminatus \\
\hline Chlamys hupeanus (Philippi) & & & & & & $x$ & \\
\hline Myochlamys foyela Ihering & & $\mathrm{x}$ & & & & & \\
\hline Modiolus sp. & & & & & & $x$ & \\
\hline Venericardia (Venericor ?) & & & & & $\mathbf{x}$ & & \\
\hline Cardium sp. & & & $\mathbf{x}$ & & & & \\
\hline Cardium patagonicum Ihering & & & & $\mathrm{x}$ & & & \\
\hline Cardium philippii Ihering & & & & $\mathrm{x}$ & & & Patagonicardium philippii \\
\hline Lahillia angulata (Philippi) & & & & & & $\mathrm{x}$ & \\
\hline Macoma sp. & & & $\mathbf{x}$ & & & & \\
\hline Lucina $s p$. & & & & $\mathbf{x}$ & & & \\
\hline Phacoides promaucana Philippi & & & & $\mathrm{x}$ & & & Miltha promaucana \\
\hline Phacoides ortmanni Ihering & & & & $\mathrm{x}$ & & & \\
\hline Miltha promaucana cruzialis (Ihering) & & & & & & $\mathbf{x}$ & \\
\hline Tellina ovalleana Philippi & & & & & & $\mathrm{x}$ & \\
\hline Lutraria $s p$. & & & & $\mathbf{x}$ & & & \\
\hline Lutraria cf. vetula Philippi & & & & & & $\mathrm{x}$ & \\
\hline Venus aff. ovallei Philippi & & & & & & $\mathrm{x}$ & \\
\hline Panopea 1 y 2 & & & & & & $\mathrm{x}$ & \\
\hline Panopea sierrana Ihering & & & & $\mathrm{x}$ & & & \\
\hline Panopea nucleus (Ihering) & $\mathbf{x}$ & & $\mathrm{x}$ & $\mathrm{x}$ & & & \\
\hline Panopea nucleus elongata (Ihering) & & $\mathbf{x}$ & & & & & \\
\hline Trochita pileus Lamarck & & $\mathrm{x}$ & & & & & Calyptraea pileus \\
\hline Natica $s p$. & & & & $\mathbf{x}$ & & $\mathbf{x}$ & \\
\hline Turritella $s p$. & & & & & & $\mathrm{x}$ & \\
\hline Turritella ambulacrum Sowerby & & & $x$ & $x$ & & & \\
\hline Struthiolaria densestriata Ihering & $\mathbf{x}$ & & & & & & Struthiolarella ornata (Sow.) \\
\hline Trophon laciniatus Martyn var. & & $\mathbf{x}$ & & & & & Trophon santacruzensis \\
\hline Voluta $s p$. & & & & & & $\mathrm{x}$ & \\
\hline Voluta triplicata Sowerby & & & & $\mathbf{x}$ & & $x$ & Proscaphella triplicata \\
\hline Tudicla sp. & & & & & & $\mathrm{X}$ & \\
\hline Cerithium cf. armoricense & & & & & & $\mathrm{x}$ & \\
\hline Campanile cf. rarinodosum Cossmann & & & & & & $\mathrm{x}$ & \\
\hline Iheringiana patagonensis (Desor) & & $\mathbf{x}$ & & & & & Iheringiella patagonensis \\
\hline
\end{tabular}

Tabla 1. Invertebrados de la Fm. Río Foyel, mencionados en la bibliografía. 1. Ihering (1904, 1907, 1914 localidades a y b); 2. Feruglio (1941); 3. González Bonorino (1944); 4. Groeber (1954); 5. Rossi de García y Levy (1984).

Invertebrates of the Rio Foyel Fm., mentioned in the bibliography. 1. Ihering (1904, 1907, 1914 localities a and b); 2. Feruglio (1941); 3. González Bonorino (1944); 4. Groeber (1954); 5. Rossi de García and Levy (1984).

y $\underline{b}$. Si bien Ihering no opinó sobre la edad de esta fauna (Tabla 1), la relacionó con la del Patagoniano del sector atlántico, a la que consideraba eocena.
Feruglio (1941: 51) reprodujo las conclusiones de Shaw (1939), pero su lista de especies difirió ligeramente de la original, pues reemplazó Turritella breantiana por 
Terebratella $\mathrm{sp}$.

Turritella aff. ambulacrum Sowerby

Polinices sp.

Fusinus patagoniensis sp. nov.

Neilo biradiata sp. nov.

Glycymeris cf. ibari (Philippi)

Pinna sp.

Brachidontes sp.

Zygochlamys sp.

Venericardia (Venericor) sp.

Loxocardium puelchum (Sowerby)

Laevicardium sp.

Panopea nucleus (Ihering)

Panopea zinsmeisteri sp. nov.

Brisaster sp.

Tabla 2. Invertebrados de la Fm. Río Foyel, descritos en este trabajo.

Invertebrates of the Rio Foyel Fm., described in this paper.

Turritella ambulacrum Sowerby, 1846, y omitió la mención de Venericardia sp., que según Shaw (en Groeber, 1954) correspondería al grupo de Venericardia (Venericor). Dado que este cardítido también es conocido en la Formación Boca Lebu, de Chile, Groeber (1954) correlacionó las lutitas de Foyel con dichos depósitos del Eoceno transandino.

Otras especies de moluscos fueron citadas por González Bonorino (1944) y atribuidas al Patagoniense (Oligoceno), mientras que Rossi de García y Levy (1984: 471-473) se refirieron a una fáunula determinada por Ubaldón (1981), del Eoceno por la presencia de Cerithium y Campanile.

La parte más alta de las lutitas de Foyel proporcionó microfaunas y microfloras. Bertels (1980) y Echevarría (1981) refirieron algunos géneros de ostrácodos al Oligoceno, pero que según Malumián et al. (1984: 494, 495, 508) podrían llegar al Mioceno más bajo. En cambio, los foraminíferos indicarían Oligoceno medio bajo (Bertels, 1980, 1993, 1994a, b).

Las microfloras de Nothofagidites y Phyllocladidites indicarían relaciones con la Formación Río Turbio, del Eoceno de la Provincia de Santa Cruz (Pöthe de Baldis, 1984: 398).

\section{ESTRATIGRAFÍA}

Cazau (1972, 1980) incluyó las lutitas del río Foyel en su Formación Rincón de Cholila, marina, integrante del Grupo Nahuel Huapi, la que fue atribuida al Patagoniano por Feruglio (1949). Sin embargo, la misma se compone de areniscas, con escasas intercalaciones de arcillitas, con laminación cruzada y ondulitas (ripples) de playa (Cazau, 1980: 1157-1158) y contiene una fauna de ostreidos, gasterópodos y equinodermos (Petersen y González Bonorino, 1947), por lo que esta secuencia correspondería a un ambiente de sedimentación más litoral que el indicado para las lutitas del río Foyel. Por este motivo, consideramos más apropiado adoptar para éstas la denominación de Formación Río Foyel (Pöthe de Baldis, 1984).

La Formación Río Foyel fue introducida por Pöthe de Baldis (1984: 393, 398) para referirse a los afloramientos marinos, lutíticos, expuestos en las márgenes del río homónimo, que contienen una microflora continental. Su perfil tipo se presenta en el valle de dicho curso de agua, frente a la Estancia de Troncoso, donde Roth (1922) recogiera los primeros fósiles y Shaw (1939) describiera la secuencia volcano-sedimentaria que allí aflora.

Litológicamente, se diferencian un tramo superior y otro inferior. En el primero predominan lutitas grises oscuras, de fractura concoidea y marcado diaclasamiento; en su mayoría aflora sobre la ruta nacional y ha proporcionado foraminíferos, ostrácodos, microfloras y restos de hojas y troncos. El segundo consiste en lutitas moradas y grises azuladas, bioturbadas por pequeños tubos horizontales, con delgadas intercalaciones de areniscas de grano fino a mediano con concreciones fosilíferas. Sus mejores afloramientos se hallan sobre el mismo curso del río, aunque son de naturaleza discontinua. Localmente se observan espesores entre $50 \mathrm{~m}$ y $60 \mathrm{~m}$, pero la potencia total de la secuencia alcanzaría los $600 \mathrm{~m}$ (Shaw, 1939), incluyendo los estratos del cerro Fortaleza, consistentes en areniscas y pelitas areniscosas, consolidadas, con estratificación planar paralela, de bajo ángulo, que alternan con areniscas conglomeráticas, pardo amarillentas, muy consolidadas; dominan los materiales piroclásticos con esporádicos y delgados niveles volcanoclásticos y calcarenitas.

La localidad fosilífera objeto del presente trabajo, ubicada sobre la margen derecha del río Foyel frente a la Estancia de Troncoso, muestra el perfil siguiente, desde el techo a la base:

$3 \mathrm{~m}$ - Pelitas masivas verde-azuladas, moderadamente consolidadas, muy diaclasadas, con fractura concoidea.

2 m - Pelitas tobáceas, gris-azuladas, moderadamente consolidadas y masivas, con concreciones.

$2 \mathrm{~m}$ - Pelitas finamente laminadas, pardas oscuras, moderadamente friables.

$5 \mathrm{~m}$ - Pelitas y areniscas finas, estratificación fina y horizontal, muy fracturadas, con concreciones bastante friables, pardo-amarillentas a pardo-rojizas.

$6 \mathrm{~m}$ - Pelitas finamente laminadas y calcarenitas macizas, interestratificadas.

Las calcarenitas, pardo amarillentas y consolidadas, contienen moldes de Turritella. Las pelitas, pardogrisáceas oscuras a azuladas y moderadamente friables, contienen bivalvos grandes.

La secuencia es estrato y granocreciente, con espesores máximos entre $1 \mathrm{~m}$ y $0,60 \mathrm{~m}$, y mínimos entre $0,10 \mathrm{~m}$ y $0,05 \mathrm{~m}$, hacia la base. Presenta una notable perturbación tectónica de dirección $\mathrm{N} 320^{\circ} \mathrm{O}$ y buzamiento $15^{\circ} \mathrm{NE}$; el diaclasamiento presenta dirección $\mathrm{N}^{\circ} \mathrm{E}$, y buzamiento $52^{\circ} \mathrm{ONO}$.

En general, las lutitas que afloran en las márgenes del río Foyel corresponden a facies de muy baja energía, formadas lejos de la costa, mientras que por encima los niveles del cerro Fortaleza indicarían una situación más costera y de mayor energía. 


\section{EDAD Y RELACIONES BIOESTRATIGRÁFICAS}

La edad atribuida a la Formación Río Foyel varía, según los autores, desde el Eoceno (Groeber, 1954) hasta el Oligoceno medio (Bertels, 1993, 1994a, b); Pöthe de Baldis (1984), sobre la base de las microfloras, la estableció entre el Eoceno tardío y el Oligoceno temprano mientras que, según los foraminíferos, llegaría al Oligoceno medio (Bertels, 1994a). Sólo Rassmuss (1922) atribuyó esta secuencia lutítica al Cretácico, lo que fue criticado por Roth (1922).

En general, el estudio de los megafósiles arroja edades algo más antiguas que el de los microfósiles, aunque esto se debería a que los primeros proceden de niveles bastante más bajos que los segundos.

La bibliografía menciona un número importante de especies (Tabla 1), principalmente moluscos, hallados en esta formación, pero sin describirlas ni ilustrarlas. Rossi de García y Levy (1984) citan la presencia de Cerithium Bruguière, 1789 y Campanile Fischer, 1884, géneros hasta ahora desconocidos en nuestras faunas marinas terciarias, aunque de gran desarrollo en aguas cálidas eocenas de otras latitudes, principalmente en las "Capas con Cardita Beaumonti" de Sind (India). Rossi de García y Levy (1984) también mencionan el género Campanile en la Formación Arroyo Verde, aflorante en la región litoral atlántica de la Provincia del Chubut, concluyendo que en Patagonia, Campanile y Cerithium, por sus afinidades con formas europeas, indicarían Eoceno medio.

Dicha edad resulta coincidente con la aportada por los representantes del Grupo Venericardia (Venericor) planicosta, de amplia representación en el Eoceno mundial, incluyendo América del Sur (Venezuela, Colombia, Ecuador, Perú, Chile y Argentina). En la Argentina, especies de este Grupo se conocen en las formaciones Río Turbio (Archangelsky, 1968), Man Aike (Furque, en Furque y Camacho, 1972) y Vaca Mahuida (Uliana, 1974), asignadas al Eoceno medio por Malumián (1990), Camacho et al. (1998) y Melchor et al. (1992), respectivamente. Otras especies que indicarían relaciones con unidades eocenas de Patagonia serían: Loxocardium puelchum (Sowerby, 1846) у Panopea nucleus (Ihering, 1899), conocidas en la Formación Río Turbio de la Sierra Baguales (Ihering, 1907), Schizaster sp., presente en la Formación El Chacay del lago Pueyrredón (Chiesa et al., 1995) y Iheringiella patagonensis (Desor, 1847), frecuente en los "Estratos con Monophoraster y Venericor" (Camacho, 1974) y la Formación San Julián (Bertels, 1970), de la costa atlántica.

Fundamentados en lo expresado precedentemente, consideramos que la edad de la megafauna del tramo inferior de la Formación Río Foyel debe atribuirse al Eoceno.

Algunas especies de la Formación Río Foyel también son conocidas en el Terciario chileno. Así, Venericardia (Venericor) se halla en la Formación Boca Lebu, considerada del Luteciense (Tavera, 1942) o del Paleoceno superior - ? Eoceno basal (Martínez Pardo, 1968); Loxocardium puelchum, Panopea nucleus y Iheringiella patagonensis integran la fauna de la Formación Guadal de Pampa Castillo, región de Aisen, Chile (Frassinetti y Covacevich, 1999) y además tienen una amplia distribución en el Eoceno patagónico. Frassinetti y Covacevich (1999) correlacionan la Formación Guadal con estratos de la región del río Mayo en el Chubut occidental, los de Meseta Buenos Aires (Ugarte, 1956), los del "Patagoniano" de la Meseta Belgrano (Riggi, 1957) y los de la Formación Centinela (Ramos, 1982), considerándola del Oligoceno tardíoMioceno temprano. Actualmente, los estratos de las mesetas Buenos Aires y Belgrano integran la Formación El Chacay (Chiesa y Camacho, 1995), eocena, y la Formación Centinela (Furque y Camacho, 1972), por hallarse coronada por una toba de $46 \mathrm{Ma}$ (Feldmann et al., 1997), correspondería al Eoceno medio.

\section{DESCRIPCIÓN DE LA FAUNA}

Los ejemplares que se describen a continuación integran la colección del ex Centro de Investigaciones en Recursos Geológicos (CIRGEO), bajo la sigla CIRGEO-PI, actualmente depositados en la División Invertebrados Fósiles del Museo Argentino de Ciencias Naturales Bernardino Rivadavia (Av. Angel Gallardo 470, 1405 Buenos Aires, Argentina). Muestran un estado de conservación precario y la edad de los mismos (Eoceno) ha sido discutida precedentemente.

La sistemática adoptada en este trabajo sigue las propuestas en las obras siguientes: Treatise on Invertebrate Paleontology Part H, 1965 (Brachiopoda), Part N, 1969 (Bivalvia), Part U, 1966 (Echinodermata 3) y Wenz, W. 1938-1944 (Gastropoda).

Figura 2. (Todos los ejemplares X 1; Colección CIRGEO-PI). a - b. Terebratella sp., n 2769; c. Turritella aff. ambulacrum Sowerby, 1846, nº 2783 a; d - e. Fusinus patagoniensis sp. nov. Holotipo no 2784 a, Paratipo n ${ }^{\circ} 2775$; f. Neilo biradiata $\mathrm{sp}$. nov. Holotipo $\mathrm{n}^{\circ} 2770 ;$ g. Pinna $\mathrm{sp} . \mathrm{n}^{\circ} 2773 ;$ h. Brachidontes $\mathrm{sp} . \mathrm{n}^{\circ} 2780 ;$ i. Zygochlamys $\mathrm{sp} . \mathrm{n}^{\circ} 2781$; j. Loxocardium puelchum (Sowerby, 1846), n 2782 b; k. Laevicardium sp., n 2774; 1. Panopea nucleus (Ihering, 1899), n 2777 a; m - n. Panopea zinsmeisteri sp. nov. Holotipo nº 2779 a.

(All specimens X 1; Collection CIRGEO-PI). a - b. Terebratella sp., $n^{\circ} 2769$; c. Turritella aff. ambulacrum Sowerby, 1846, $n^{\circ} 2783$ a; $\mathbf{d}-\mathbf{e}$. Fusinus patagoniensis sp. nov. Holotype $n^{\circ} 2784$ a, Paratype $n^{\circ} 2775$; f. Neilo biradiata sp. nov. Holotype $n^{o}$ 2770; g. Pinna sp., $n^{\circ} 2773$; h. Brachidontes sp., $n^{\circ} 2780$; i. Zygochlamys $s p ., n^{\circ} 2781$; j. Loxocardium puelchum (Sowerby, 1846), $n^{\circ} 2782$ b; k. Laevicardium sp., $n^{\circ}$ 2774; 1. Panopea nucleus (Ihering, 1899), $n^{\circ} 2777 a ; \mathbf{m}-\mathbf{n}$. Panopea zinsmeisteri sp. nov. Holotype $n^{\circ} 2779 a$. 

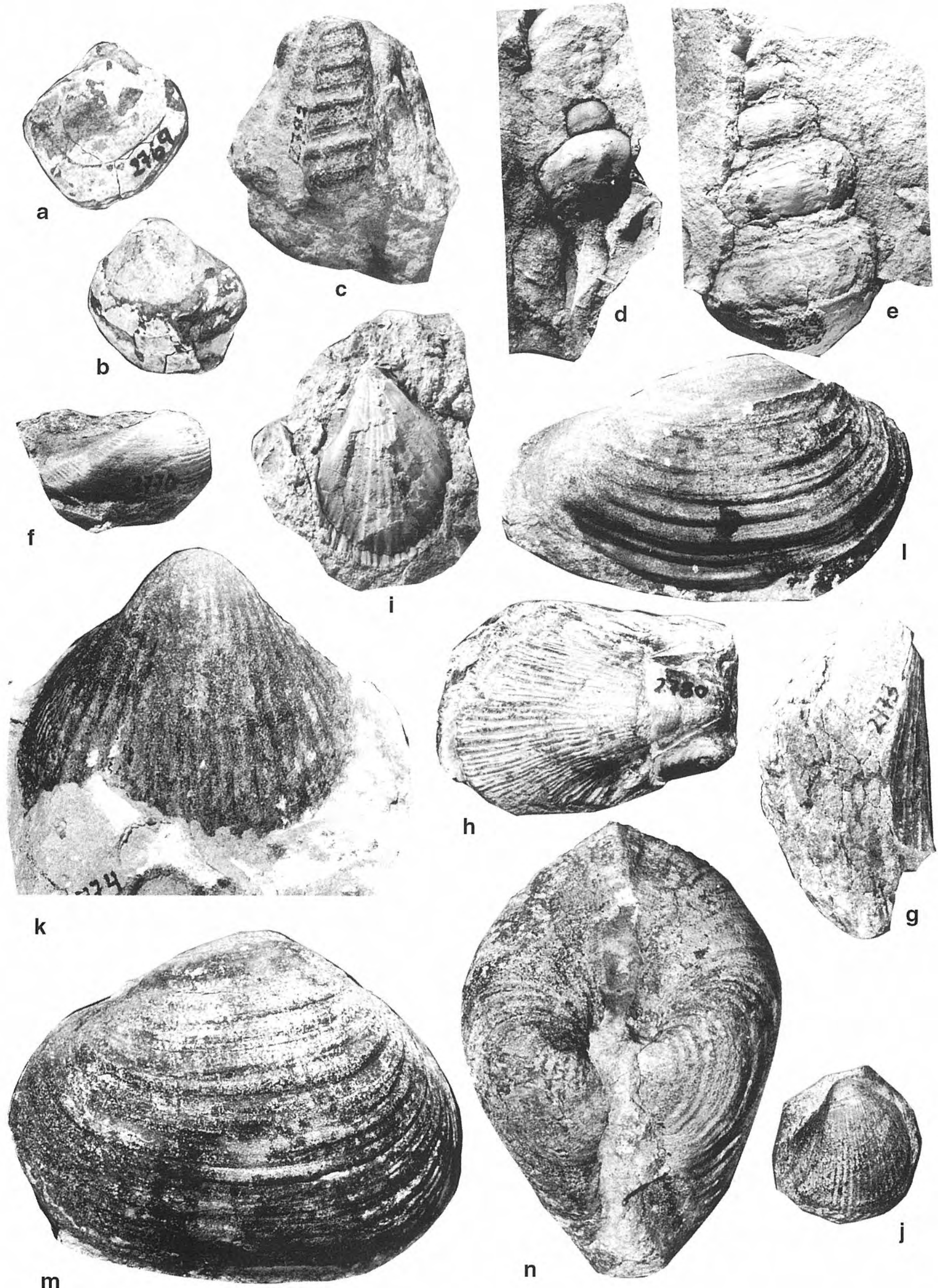
PHYLUM BRACHIOPODA Duméril, 1806

ORDEN TEREBRATULIDA Waagen, 1883

Familia Terebratellidae King, 1850

Subfamilia Terebratellinae King, 1850

Género Terebratella d'Orbigny, 1847

Especie tipo: Terebratula chilensis Broderip, 1833.

\section{Terebratella $\mathrm{sp.}$}

Fig. 2 a, b

Material: Una concha (CIRGEO-PI 2769), deformada, con ambas valvas muy erosionadas.

Descripción: Concha de tamaño mediano, contorno ligeramente ovalado, aparentemente biconvexa. Valva ventral con un pliegue medio marcado, que determina un borde anterior levemente plegado; valva dorsal con un seno medio suave sobre su mitad anterior. Umbo destacado, poco curvado, ocupado por un foramen grande, subredondeado, limitado inferiormente por placas deltidiales mal conservadas. Superficie lisa con escasas líneas de crecimiento comarginales.

Dimensiones (en mm): Ejemplar CIRGEO-PI 2769, deformado (Fig. 2 a, b): ancho, 29; largo, 29.

Observaciones: En el Terciario Inferior patagónico se conocen especímenes, a veces determinados a nivel genérico, que, por sus características generales, se aproximan al aquí descripto. Feruglio (1936; p. 171, lám. 20, figs. 1 a-e), con la denominación de Terebratella venter Ihering, 1903, ilustra un ejemplar del arroyo de los Perros (Lago Argentino), de contorno bastante similar, pero cuyo tamaño sería más pequeño; Chiesa et al. (1995; p. 31, lám. 1, fig. 2 a-b) describen Terebratella $B$, del Eoceno del lago Pueyrredón, muy similar por su tamaño y forma general, pero con foramen más pequeño; Terebratella gigantea Ortmann (1902; p. 78, lám. 14, fig. 2 a-f), del cabo Buentiempo, sería de mucho mayor tamaño, con el umbo más erecto y las placas deltidiales más desarrolladas.

Los ejemplares más similares al nuestro corresponden a Terebratella sp. 2, procedente de la Formación Guadal (Niemeyer, 1975; Niemeyer et al., 1984) en Pampa Castillo, Región de Aisen, Chile, ilustrada por Frassinetti y Covacevich (1999; p. 15, lám. 2, figs. 3-4, non fig. 2), que concuerda tanto en tamaño como en las características generales externas, si bien nuestra Terebratella muestra un plegamiento del borde anterior no observable en la especie chilena.

PHYLUM MOLLUSCA Linnaeus, 1758

CLASE GASTROPODA Cuvier, 1797

ORDEN MESOGASTROPODA Thiele, 1925

Familia Turritellidae Woodward, 1851

Género Turritella Lamarck, 1799
Turritella aff. ambulacrum Sowerby, 1846

Fig. $2 \mathrm{c}$

1902 Turritella ambulacrum Sowerby; Ortmann, 192, lám. 31, fig. 13 a.

1908 Turritella ambulacrum Sowerby; Steinmann y Wilckens, 50, lám. 6, fig. 1,2.

1999 Turritella ambulacrum Sowerby; Frassinetti y Covacevich, 45, lám. 9, fig. 8.

Material: 17 moldes internos incompletos (CIRGEO-PI 2783) y muy mal conservados.

Descripción: Concha cónico-alargada, de tamaño mediano a grande; espira con vueltas que aumentan regularmente de tamaño, más anchas que altas, cóncavas en su parte media, separadas por una sutura rectilínea, algo inclinada, situada en una concavidad; abapical y adapicalmente, cada vuelta presenta engrosamientos o cíngulos, el adapical mucho más desarrollado que el abapical; entre ambos cíngulos se observan aproximadamente 5 líneas espirales finas, que también se repetirían en la concavidad sutural. Regiones apical y apertural no conservadas.

Dimensiones (en mm): Ejemplar CIRGEO-PI 2783 a (Fig. 2 c), última vuelta de la espira, ancho 8 ; altura, 5 .

Observaciones: Según Ortmann (1902) esta especie es muy variable, lo que fue confirmado por Ihering (1907), quien diferenció diversas variedades o subespecies que son de dificultoso reconocimiento. Turritella ambulacrum es frecuentemente mencionada en el Terciario patagónico y chileno, tanto en estratos eocenos como más jóvenes, pero muchas de estas citas necesitarían confirmación. La precaria conservación de nuestro material, no permite efectuar una determinación sistemática segura.

Familia Naticidae Forbes, 1838

Género Polinices Montfort, 1810

Especie tipo: Polinices albus Montfort, 1810.

\section{Polinices sp.}

Material: Tres moldes internos (CIRGEO-PI 2785), precariamente conservados.

Observaciones: Se dispone de un ejemplar de pequeño tamaño y otros dos mayores, aunque todos ellos muestran sólo restos de la última vuelta y de una espira muy reducida.

Por sus características generales conservadas, Polinices sp. se aproxima a Polinices subtenuis Ihering (1897, p. 284, fig. 13), del Terciario aflorante en la desembocadura del río Santa Cruz y que también se presenta en la Formación La Meseta del Eoceno antártico (Wilckens, 1911, p. 21, fig. 24; Stilwell y Zinsmeister, 1992, p. 110, lám. 14, figs. n, o).

Especie tipo: Turbo terebra Linnaeus, 1758. 
ORDEN NEOGASTROPODA Thiele, 1925

Superfamilia Buccinoidea Rafinesque, 1815

Familia Fasciolariidae Gray, 1853

Subfamilia Fusininae Swainson, 1840

Género Fusinus Rafinesque, 1815

Especie tipo: Murex colus Linnaeus, 1758.

\section{Fusinus patagoniensis sp.nov.}

Fig. 2 d, e

Material: Cuatro moldes internos incompletos (Holotipo CIRGEO-PI 2784) y otro (Paratipo CIRGEO-PI 2775) con el canal sifonal.

Diagnosis: Fusinus con la base de la última vuelta recorrida por cuatro cordones espirales gruesos y muy distanciados entre sí.

Fusinus with 4 strong spiral ribs on the base of the last whorl, separated by wide spaces.

Descripción: Concha grande, sólida, fusiforme; espira elevada, con aproximadamente 5 vueltas, subrectangulares, subnodosas; sutura impresa en una depresión entre las vueltas, rectilínea y subhorizontal. Ornamentación constituida por cordones espirales de grosor mediano en la parte central de la vuelta, más finas en el espacio adapical y más gruesas en el abapical, donde se observan cuatro de ellas de gran grosor separadas por espacios amplios y lisos; costillas axiales notables, algo nodosas, en número aproximado de 10 y que se extienden principalmente sobre la parte media de la vuelta. Abertura subovalada y canal sifonal rectilíneo, bien desarrollado.

Dimensiones (en mm): Holotipo CIRGEO-PI 2784 a (Fig. 2 e), altura de la espira (parcial), 30; ancho de la última vuelta, 32; altura, 25. Paratipo CIRGEO-PI 2775 (Fig. 2 d), última vuelta: ancho, 17; altura, 10; longitud del canal sifonal, 23.

Derivatio nominis: Procedente de la Patagonia.

Observaciones: Los ejemplares disponibles son moldes incompletos y bastante erosionados, faltando las vueltas iniciales. Fusinus se caracteriza por una espira grande, elevada y esbelta, ornamentación espiral normalmente gruesa y canal sifonal anterior largo y recto (de Stilwell y Zinsmeister, 1992, p. 132). El género Falsicolus Finlay, 1930, tiene una carena periférica pronunciada, mientras que en Penion Fischer, 1884, la espira se halla menos desarrollada.

Fusinus es un género de distribución mundial y muy difundido en la región austral, donde está representado por fósiles en el Terciario de Nueva Zelanda, Australia y Antártida; actualmente habita en los mares de Nueva Zelanda y América del Sur. En el noreste brasileño viven: Fusinus brasiliensis (Grabau, 1904), con cordones espirales más gruesos y espira más corta; Fusinus closter (Philippi, 1850) con costillas espirales más gruesas y las axiales casi obsoletas en la última vuelta; Fusinus strigatus (Philippi, 1851) con costillas axiales muy marcadas y extendidas de sutura a sutura, y Fusinus marmoratus (Philippi, 1846) con las costillas axiales reducidas a nodosidades; Fusinus frenguellii (Carcelles, 1953), que habita desde Río de Janeiro hasta la Argentina (Puerto Quequén) es una forma mucho más estilizada.

Fusinus patagoniensis sp. nov. tiene gran similitud con Fusinus graciloaustralis Stilwell y Zinsmeister (1992, p. 132, lám. 18, figs. c-d), del Eoceno de la isla Marambio (Seymour), de la Antártida, cuyas vueltas son más altas con relación al ancho y tiene 12 prominentes costillas axiales; Fusinus suraknisos Stilwell y Zinsmeister (1992, p. 131, lám. 18, figs. a-b, e), de la misma localidad y edad, posee una espira menos elevada.

CLASE BIVALVIA Linnaeus, 1758

SUBCLASE PALAEOTAXODONTA Korobkov, 1954 ORDEN NUCULOIDA Dall, 1889

Superfamilia Nuculanoidea H. Adams y A. Adams, 1858 Familia Malletiidae Adams y Adams, 1858 Género Neilo Adams, 1852

Especie tipo: Neilo cumingii Adams, 1854.

\section{Neilo biradiata sp. nov.}

Fig. $2 \mathrm{f}$

Material: Un molde interno de valva derecha (Holotipo CIRGEO-PI 2770), incompleto, del río Foyel.

Diagnosis: Neilo con el área posterior recorrida por dos estrías radiales.

Neilo with the posterior area showing two weak radial ribs.

Descripción: Concha de tamaño mediano, transversalmente alargada y contorno subrectangular. Umbo poco destacado, ubicado a conservado, el posterior descendente y ligeramente cóncavo; borde ventral suavemente convexo. Extremidad anterior no conservada, la posterior truncada oblicuamente, formando un ángulo agudo y poco saliente con el borde dorsal, mientras que con el ventral el ángulo es redondeado. Desde el umbo parte hacia el ángulo postero-ventral, una faja angosta, subaplanada, limitada por bordes destacados; entre dicha área y el borde dorsal posterior, la superficie valvar es ligeramente cóncava y está recorrida por dos estrías radiales débiles. Superficie valvar con unos 25 cordones comarginales, uniformes, separados por espacios amplios.

Dimensiones (en mm): Holotipo CIRGEO-PI 2770 (Fig. 2 f); longitud, 35, altura, 20.

Derivatio nominis: Alude a las dos estrías radiales que surcan la superficie del área posterior.

Observaciones: Neilo biradiata sp. nov. se diferencia de las especies del género descritas para nuestro país, por tener su área posterior recorrida por dos estrías radiales y que limitan un sector subaplanado. En lo que respecta al 
resto de sus caracteres, se asemeja a Neilo subornata (Feruglio, 1936, p. 229, lám. 23, fig. 25) del Salamanquense del Golfo San Jorge, si bien esta especie es más alargada y su umbo sería más prominente; Neilo ornata ortmanni Erdmann y Morra (1985, p. 290, lám. 1, figs. 1 a-c), de la Formación San Julián, es más globoso y su área posterior está recorrida por una estría radial paralela al borde dorsal; Neilo doellojuradoi Malumián, Camacho y Gorroño (1978, p. 272, lám. 4, figs. 1,2), del Terciario de Tierra del Fuego, carece de estrías en la parte posterior y tendría mayor número de costillas comarginales; Neilo volckmanni (Philippi, 1887, p. 194, lám. 41, fig. 9), del Terciario chileno, es una forma más corta, con el umbo más destacado y el borde ventral más convexo.

\section{SUBCLASE PTERIOMORPHIA Beurlen, 1944 ORDEN ARCOIDA Stoliczka, 1871 Superfamilia Limopsoidea Dall, 1895 \\ Familia Glycymerididae Newton, 1922 \\ Subfamilia Glycymeridinae Newton, 1922 Género Glycymeris Da Costa, 1778}

Especie tipo: Arca orbicularis Da Costa, 1778 (= Arca glycymeris Linnaeus, 1758).

\section{Glycymeris cf. ibari (Philippi, 1887)}

1887 cf. Pectunculus ibari Philippi, 183-184, lám. 40, fig. 3. 1902 Glycymeris ibari (Philippi); Ortmann, 94, lám. 26, fig. $1 \mathrm{a}-\mathrm{c}$.

1991 Glycymeris cf. G. ibari (Philippi); Griffin, 126, fig. 4.1.

Material: Un molde interno de valva izquierda (CIRGEOPI 2771) pobremente conservado.

Dimensiones (en mm): Longitud, 103; altura, 100; espesor, 4.

Observaciones: El único ejemplar disponible es un molde interno que, en sus características generales, concuerda bastante bien con el atribuido por Griffin (1991) a Glycymeris cf. G. ibari (Philippi, 1887), procedente de la parte superior de la Formación Río Turbio. Glycymeris ibari es una especie del Terciario de Punta Arenas, Chile, a la que Ihering (1907, p. 240) consideró sinónimo de su Glycymeris cuevensis Ihering, 1897, pero que, a juzgar por las características de ambas, podrían ser dos especies diferentes. Ortmann (1902, p. 96-97) refiere que halló ejemplares grandes completamente idénticos a los de Punta Arenas, en el lago Pueyrredón, donde afloran estratos que serían de edad equivalente a los del río Foyel.

ORDEN MYTILOIDA Férussac, 1822

Superfamilia Pinnoidea Leach, 1819

Familia Pinnidae Leach, 1819

Género Pinna Linnaeus, 1758

Especie tipo: Pinna rudis Linnaeus, 1758.

\section{Pinna sp.}

Fig. $2 \mathrm{~g}$

Material: Un fragmento con resto de concha (CIRGEO-PI 2773).

Dimensiones (en mm): Longitud (incompleta) 45; altura (incompleta), 33 .

Descripción: El fragmento disponible correspondería a la porción anterior de la concha, no conservándose la parte umbonal. Se trataría de una valva izquierda y un resto de la derecha, de contorno triangular y sección ovalada a subromboidal, que se expande rápidamente hacia la extremidad posterior (no conservada); la parte media está recorrida por una carena suave y redondeada; el borde dorsal es rectilíneo y el ventral se inicia recto pero pronto se hace convexo. La parte dorsal muestra unas 4 costillas radiales, algo agudas, separadas por espacios amplios; la parte dorsal presenta su superficie muy erosionada, lo que impide observar sus características.

Observaciones: Una característica de nuestro fragmento de Pinna sp. sería el escaso número (4) de costillas radiales existentes en el área dorsal, pero su precaria conservación y su reducido tamaño no permiten efectuar comparaciones confiables. En general, las especies de Pinnidae descriptas para el Terciario austral suramericano e incluso la Antártida tendrían un mayor número de costillas radiales dorsales. Entre la fauna de esta localidad, mencionada por Rossi de García y Levy (1984), figura una Pinna cf. tumida Philippi (1887, p. 206, lám. 43, fig. 8) del Terciario Inferior de Lebu (Chile), la que tendría una sección pentagonal. Pinna magellanica (Ihering, 1907) muestra mayor número de costillas radiales. Pinna semicostata Philippi (1887, p. 206, lám. 43, fig. 10) posee costillas radiales débiles. Pinna robusta Chiesa, Parma y Camacho (1995, p. 39, lám. 3, figs. 1, 2), del Eoceno del lago Pueyrredón, es una forma de tamaño mucho mayor.

\section{Superfamilia Mytiloidea Rafinesque, 1815 \\ Familia Mytilidae Rafinesque, 1815 \\ Subfamilia Mytilinae Rafinesque, 1815 \\ Género Brachidontes Swainson, 1840}

Especie tipo: Modiola sulcata Lamarck, 1819 (non Lamarck, 1805).

\section{Brachidontes sp. \\ Fig. $2 \mathrm{~h}$}

Material: Un molde interior de valva derecha (CIRGEO-PI 2780) con ornamentación conservada sólo en su parte posterior.

Dimensiones (en mm): Longitud (incompleta), 55; altura (incompleta), 40. 
Descripción: Valva de tamaño mediano, subtriangular, umbo aparentemente subterminal y parte posterior rápidamente expandida mostrando una convexidad marcada a lo largo de su parte media. Superficie recorrida por numerosas costillas radiales separadas por surcos aproximadamente de igual ancho, bifurcadas a partir de la región umbonal.

Observaciones: “Mytilus ramosus" Philippi (1887, p. 200, lám. 43, fig. 2) del Terciario de Lebú (Chile), tiene la mayor convexidad desplazada hacia la región ventral. Brachidontes andinus Ortmann (1902, p. 122, lám. 24, fig. 4), del Eoceno del lago Pueyrredón, es una forma mucho más pequeña y en la región media presenta una convexidad bien marcada, de recorrido curvo. Frassinetti y Covacevich $(1999$, p. 21, lám. 3, fig. 2,3) atribuyen a este género una forma de la Formación Guadal (Chile) que es más subtrapezoidal y con la arista media más atenuada, que se asemeja mucho a nuestro Brachidontes sp., excepto en que es de mucho menor tamaño. Brachidontes ortmanni Chiesa, Parma y Camacho (1995, p. 36, lám. 2, fig. 1) es una especie muy similar a la chilena.

ORDEN PTERIOIDA Newell, 1965

Superfamilia Pectinoidea Rafinesque, 1815

Familia Pectinidae Rafinesque, 1815

Género Zygochlamys Ihering, 1907

Especie tipo: Pecten geminatus Sowerby, 1846.

\section{Zygochlamys sp.}

Fig. 2 i

Material: Una valva izquierda juvenil (CIRGEO-PI 2781).

Dimensiones (en mm): Longitud, 25; altura, 40.

Descripción: Concha pequeña, más alta que larga, subtriangular, ligeramente convexa. Aurícula posterior pequeña, la anterior no conservada. Ornamentación constituida por costillas radiales simples de grosor desigual.

Observaciones: El único molde disponible, por sus características generales, se asemeja a Zygochlamys geminatus (Sowerby, 1846), del Terciario Inferior patagónico, pero su precaria conservación impide una determinación más exacta. De esta misma localidad, Ihering (1914, p. 33, lám. 1, fig. 3) describió Myochlamys foyela $\mathrm{n}$. sp. sobre la base de ejemplares que recogiera Hauthal en la localidad b. Si bien esta especie parece corresponder igualmente al género Zygochlamys, en cambio se diferencia de la aquí considerada, principalmente por su contorno redondeado y sus costillas radiales más finas.

En la aceptación de Zygochlamys como un género distinto de Chlamys Röding, 1798, se ha seguido a Morra (1995).
SUBCLASE HETERODONTA Neumayr, 1884

ORDEN VENEROIDA H. Adams y A. Adams, 1856

Superfamilia Carditoidea Fleming, 1820

Familia Carditidae Fleming, 1828

Género Venericardia Lamarck, 1801

Especie tipo: Venericardia imbricata Lamarck (= Venus imbricata Gmelin, 1791), por designación posterior de Schmidt, 1818.

Subgénero Venericor Stewart, 1930

Especie tipo: Venericardia planicosta Lamarck.

Venericardia (Venericor) sp.

Material: Dos moldes internos fragmentarios (CIRGEO-PI $3002 a$, b) con restos de impresiones de la ornamentación.

Observaciones: Groeber (1954, p. 40), refiriéndose a los esquistos de Foyel, expresa que según Shaw, su fauna contendría representantes de Venericardia (Venericor?), por lo que dichos estratos serían comparables a los de Arauco (Boca Lebu, Chile) y de edad Eoceno Inferior, lo mismo que en Perú, Colombia y Venezuela. Los fragmentos valvares de nuestra colección, a pesar de su deficiente estado de conservación, confirmarían así la presencia de dicho bivalvo tan característico del Eoceno mundial, en el tramo inferior de la sucesión del río Foyel.

Superfamilia Cardioidea Lamarck, 1809

Familia Cardiidae Lamarck, 1809

Subfamilia Cardiinae Lamarck, 1809

Género Loxocardium Cossmann, 1886

Especie tipo: Cardium formosum Deshayes, 1858.

\section{Loxocardium puelchum (Sowerby, 1846)} Fig. $2 \mathrm{j}$

1846 Cardium puelchum Sowerby, 251, lám. 2, fig. 15 (1876, 607, lám. 2, fig. 15).

1902 Cardium puelchum Sowerby; Ortmann, 133, lám. 27, fig. 7.

1907 Cardium puelchum Sowerby; Ihering, 292.

1995 Loxocardium puelchum (Sowerby); Chiesa, Parma y Camacho, 44, lám. 2, fig. 8.

1999 Trachycardium puelchum (Sowerby); Frassinetti y Covacevich, 28, lám. 5, figs. 9, 10.

Material: Dos moldes internos (CIRGEO-PI 2782 a, b), precariamente conservados.

Dimensiones (en mm): Ejemplar CIRGEO-PI 2782 b (Fig. 2 j): longitud, 30; altura, 25; espesor (1/2), 10.

Descripción: Concha pequeña, subglobosa, subtrigonal, ligeramente asimétrica; umbo destacado desde el que desciende una carena hasta el ángulo postero-ventral que 
limita un área posterior triangular y aplanada. Borde ventral convexo, borde posterior rectilíneo, formando una angulosidad con el ventral. Superficie recorrida por numerosas costillas radiales poco marcadas debido al desgaste por erosión.

Observaciones: Sowerby (1846) describió bajo esta denominación una concha juvenil, pequeña, subcarenada posteriormente, de la Provincia de Santa Cruz. Su ilustración, además, muestra una truncación posterior, que justificaría su asignación a Loxocardium. Nuestros ejemplares exhiben muy bien estas características de la especie de Sowerby. También se han hallado otros representantes de mayor tamaño; así, Ihering (1907, p. 292) refiere que Hauthal le proporcionó una concha grande proveniente de la Sierra Baguales (Ihering, 1907), mientras que Chiesa, et al. (1995) atribuyeron a esta especie un ejemplar del Eoceno del lago Pueyrredón, y Frassinetti y Covacevich (1999) describieron otro ejemplar de la Formación Guadal (Chile). Si bien las conchas de mayor tamaño conservan las características taxonómicas de la especie, parece que, en ellas, la carena posterior es mucho más suave.

Subfamilia Laevicardiinae Keen, 1936

Género Laevicardium Swainson, 1840

Especie tipo: Cardium oblongum Gmelin, 1791.

\section{Laevicardium $\mathrm{sp}$.}

Fig. 2 k

Material: Un molde interno de valva derecha (CIRGEO-PI 2774).

Dimensiones (en mm): Altura (aproximada), 70; longitud (aproximada), 65; espesor (aproximado), 3.

Descripción: Concha grande, algo menos alta que larga, globosa, umbo destacado, situado casi centralmente. Bordes dorsales anterior y posterior cortos y descendentes; borde lateral anterior regularmente convexo, el posterior ligeramente curvado; borde ventral abiertamente convexo. Ornamentación sobre las partes anterior y central constituida por unas 17-18 costillas radiales lisas, separadas por espacios aproximadamente de igual ancho; sobre la parte posterior valvar se observan unas 15 costillas radiales mucho más delgadas.

Observaciones: Philippi (1887, p. 170, lám. 38, fig. 4) describió Cardium magellanicus n. sp. basándose en un molde del Terciario de Punta Arenas (Chile), muy mal conservado, que tiene su superficie recorrida por unas 50 costillas radiales, mejor conservadas en la parte central de la valva, especie que parecería tener alguna similitud con la forma del río Foyel, si bien el número de costillas radiales sería muy superior. Feruglio (1936, p. 175, lám. 20, fig. 5) comparó con esta misma especie un ejemplar del Patagoniano del arroyo Calafate, por otra parte, muy parecido a nuestra forma del río Foyel, aunque el número de costillas en ambos sería inferior al de Punta Arenas. Cardium ameghinoi Ihering, 1907, del Terciario de Santa Cruz, es de menor tamaño y su ornamentación consiste en costillas anchas entre las cuales hay 4 más angostas.

ORDEN MYOIDA Stoliczka, 1870

Superfamilia Hiatelloidea Gray, 1824

Familia Hiatellidae Gray, 1824

Género Panopea Menard de la Groye, 1807

Especie tipo: Panopea aldrovandi Menard de la Groye (= Mya glycymeris Born, 1778) por designación posterior, Children, 1823 (ICZN Opinion 1414, 1986).

\section{Panopea nucleus (Ihering, 1899)}

Fig. 21

1899 Glycimeris nucleus Ihering, 23, lám. 1, fig. 7.

1907 Panopea nucleus (Ihering); Ihering, 326, lám. 12, figs. $85 \mathrm{a}, \mathrm{b}$.

1914 Panopea nucleus elongata (Ihering); Ihering, 64.

1936 Panopea nucleus (Ihering); Feruglio, 180, lám. 20, figs $6 \mathrm{a}, \mathrm{b}$.

1999 Panopea nucleus (Ihering); Frassinetti y Covacevich, 41, lám. 8, figs. 2-4.

Material: Dos moldes internos completos (CIRGEO-PI $2777 \mathrm{a}, \mathrm{b})$.

Dimensiones (en mm): CIRGEO-PI 2777 a (Fig. 2 1): longitud, 74; altura, 45; espesor (total), 37; CIRGEO-PI 2777 b: longitud, 80; altura, 44; espesor (total), 40 .

Descripción: Concha de tamaño mediano, de contorno ovalado-alargado, globosa; umbo desplazado hacia la extremidad anterior y situado aproximadamente a $1 / 3$ de la longitud total. Extremidad anterior corta y convexa; extremidad posterior alargada y estrecha. Borde dorsal subrectilíneo; borde ventral suavemente convexo a rectilíneo en la parte media. Ornamentación de pliegues comarginales, entre los que se observan otros más débiles. Hiancia en ambos extremos, el posterior más abierto que el anterior.

Observaciones: Panopea nucleus es una especie muy distribuida en el Terciario Inferior de la Provincia de Santa Cruz (Sierra Baguales, San Julián, cabo Tres Puntas, Corral Foyel) y también conocida en la Formación Guadal, en Chile (Frassinetti y Covacevich, 1999). Ihering (1914) consideró que el ejemplar de Corral Foyel era una forma poco alta, alargada y con el margen ventral ligeramente cóncavo, por lo que constituiría una nueva subespecie, que denominó Panopea nucleus elongata subespecie n. Además (Ihering, 1907, p. 326) observó que, en el ejemplar del cabo Tres Puntas, la mitad anterior de la concha muestra estrías radiales muy finas, que no son visibles en la figura correspondiente, como ya destacara Ortmann (1902, p. 153). 


\begin{tabular}{|c|c|c|c|c|}
\hline RIO TURBIO & \begin{tabular}{|l} 
SUR LAGO \\
ARGENTINO \\
\end{tabular} & $\begin{array}{l}\text { NORTE LAGO } \\
\text { ARGENTINO } \\
\end{array}$ & RIO FOYEL & EDAD \\
\hline $\begin{array}{l}\text { Fm. Santa Cruz } \\
\text { (Continental) }\end{array}$ & $\begin{array}{l}\text { Fm. Santa Cruz } \\
\text { (Continental) }\end{array}$ & $\begin{array}{l}\text { Fm. Santa Cruz } \\
\text { (Continental) }\end{array}$ & & Mioceno \\
\hline & & & & Oligoceno \\
\hline & & $\begin{array}{l}\text { Fm. El Chacay } \\
\text { (Marino) }\end{array}$ & \multirow{4}{*}{$\begin{array}{l}\text { Fm. Río Foyel } \\
\text { (Parte Inferior, } \\
\text { Marino) }\end{array}$} & \multirow{4}{*}{$\begin{array}{l}\text { Eoceno medio- } \\
\text { superior }\end{array}$} \\
\hline $\begin{array}{l}\text { Fm. Arroyo Oro } \\
\text { (Sección Superior, } \\
\text { Marino) }\end{array}$ & Fm. Centinela (Marino) & \multirow[t]{2}{*}{$\begin{array}{l}\text { Fm. Río Leona } \\
\text { (Continental) }\end{array}$} & & \\
\hline $\begin{array}{l}\text { Fm. Río Guillermo } \\
\text { (Continental) }\end{array}$ & $\begin{array}{l}\text { Fm. Río Leona } \\
\text { (Continental) }\end{array}$ & & & \\
\hline $\begin{array}{l}\text { Fm. Río Turbio } \\
\text { (Marino y Continental) }\end{array}$ & $\begin{array}{l}\text { "Estratos Cerro Palique" } \\
\text { (Marino) }\end{array}$ & $\begin{array}{l}\text { Fm. Man Aike } \\
\text { (Marino) }\end{array}$ & & \\
\hline $\begin{array}{l}\text { Fm. Cerro Dorotea } \\
\text { (Marino y mixto) }\end{array}$ & & & "Serie Andesítica" & $\begin{array}{l}\text { Paleoceno- Eoceno } \\
\text { temprano }\end{array}$ \\
\hline
\end{tabular}

Figura 3. Cuadro de correlación de las principales unidades marinas eocenas que afloran en la región occidental patagónica. Correlation chart of the main eocene marine units that outcrop in the western region of Patagonia.

\section{Panopea zinsmeisteri sp. nov.}

Fig. $2 \mathrm{~m}, \mathrm{n}$

Material: 9 moldes internos (CIRGEO-PI 2799) completos pero deformados.

Diagnosis: Panopea grande, de contorno subtriangular a subtrapezoidal, globosa.

Panopea large-sized, of subtriangular to subtrapezoidal outline, inflated.

Descripción: Concha grande, de contorno subtriangular a subtrapezoidal, muy globosa; umbo subcentral, poco destacado; borde dorsal anterior corto, rectilíneo, levemente inclinado, que forma con el anterior un ángulo suave; borde dorsal posterior algo más largo que el anterior, más inclinado y pasando al posterior sin angulosidad. Borde lateral anterior convexo, el posterior subtruncado, limitando una extremidad menos elevada y más saliente que la anterior; borde ventral ampliamente convexo, casi rectilíneo en su parte central. Hiancia bien desarrollada. Ornamentación de pliegues comarginales, más angostos y numerosos ventralmente.

Dimensiones (en mm): Holotipo CIRGEO-PI 2779 a (Fig. 2 $\mathrm{m}, \mathrm{n}$ ): longitud, 85; altura, 70; espesor (total), 60 .

Derivatio nominis: Dedicada al Dr. William J. Zinsmeister por sus importantes contribuciones a la bioestratigrafía y paleobiogeografía de la región austral.

Observaciones: Panopea zinsmeisteri sp. nov. tiene mucha similitud con Panopea nucleoides Wilckens (1911, p. 20, lám. 1, fig. 21) del Terciario Inferior antártico, si bien esta especie es más alargada y su borde ventral es totalmente convexo. En el Daniense de Punta Peligro se conoce Panopea sp. nov. II (Feruglio, 1936, p. 243, lám. 24, figs. 23-25) de mucho menor tamaño, contorno más triangular, muy globosa y con pliegues comarginales más regulares.

Otras especies del Terciario austral presentan diferencias más notables, tal es el caso de Panopea sierrana Ihering (1907, p. 328, lám. 13, fig. 88), de contorno rectangular y extremidad anterior subtruncada; Panopea subsymmetrica (Ortmann, 1902, p. 153, lám. 29, fig. 6), ovalada y con ambos extremos más o menos de igual altura; Panopea pilsbryi Ortmann (1902, p. 154, lám. 29, fig. 7), de contorno ovalado y umbo subcentral muy destacado; Panopea bagualesia Ihering (1907, p. 325 , lám. 13, figs. 86 a, b), cuya extremidad anterior se halla oblicuamente truncada; Panopea philippii Zinsmeister (1984, p. 1525, figs. 10 i, k), de contorno subrectangular; Panopea undatoides (Ortmann, 1899, p. 429-430; 1902, p. 151, lám. 30, fig. 3), subrectangular y con pliegues de dos tamaños como en $P$. zinsmeisteri sp. nov.; y Panopea clausa Wilckens (1910, p. 68-69, figs. $10 \mathrm{a}, \mathrm{b})$, subrectangular y de menor tamaño.

\section{PHYLUM ECHINODERMATA Bruguière, 1791 CLASE ECHINOIDEA Leske, 1778 ORDEN SPATANGOIDA Claus, 1876 Familia Schizasteridae Lambert, 1905 Género Schizaster L. Agassiz, 1836}

Especie tipo: Schizaster studeri L. Agassiz, 1836, 185; por designación subsiguiente del $13^{\circ}$ Congreso Internacional de Zoología de París: Opinión 209, 1948 (Bulletin of the Zoological Nomenclature London 4, 527). 


\section{Schizaster? sp.}

Determinación sistemática y descripción realizada por la Lic. Graciela Parma.

Material: Un ejemplar incompleto preservado como molde secundario donde pueden observarse parte de los caracteres de la superficie aboral, periprocto y borde del peristoma (CIRGEO-PI 2786). Procedencia: río Foyel.

Dimensiones del endoesqueleto (en mm): Longitud (L), 43; altura, $32,5 \% \mathrm{~L}$.

Descripción: Endoesqueleto de tamaño mediano, longitud (L) $43 \mathrm{~mm}$, altura $32,5 \% \mathrm{~L}$; más largo que ancho, ancho máximo en el centro; aplanado, altura máxima posterior al centro; borde posterior redondeado. Sistema apical no conservado, posterior, ubicado a una distancia del margen anterior igual a $69,7 \%$ de la longitud. Ambulacro anterior III no petaloideo, ubicado en un surco amplio; zonas poríferas anchas. Pétalos anteriores (II, IV) extendiéndose $2 / 3$ de la distancia desde el sistema apical al margen, deprimidos, curvándose ligeramente hacia la parte anterior. Pétalos posteriores (I y V) más cortos que los anteriores, extendiéndose $1 / 4$ de la distancia desde el sistema apical al margen, divergentes. Peristoma anterior, ubicado a una distancia desde el borde anterior igual al 20\%L. Periprocto ubicado sobre truncamiento posterior, más alto que ancho. Fasciolas no conservadas.

Observaciones: El carácter aplanado y elongado del endoesqueleto, la presencia de un ambulacro III amplio y profundo, y la posición posterior del sistema apical recuerdan al género Brisaster Gray, 1855. Lamentablemente, el grado de conservación del ejemplar estudiado no permite observar otros caracteres diagnósticos de este género, tales como el desarrollo de la fasciola peripetalífera y el número de poros genitales. Por lo tanto preferimos, hasta contar con más y mejor material, asignar este especimen, si bien con reservas, al género Schizaster.

Por su aspecto general, el ejemplar aquí considerado muestra gran semejanza con "Schizaster" iheringi de Loeiol presente en numerosas localidades del Terciario de Argentina (Formaciones San Julián, El Chacay y Chenque).

\section{CONCLUSIONES}

Los sedimentos de la Formación Río Foyel fueron depositados, durante el Eoceno, en un "Mar Andino" extendido a lo largo de la región occidental patagónica y comunicado con el Océano Pacífico con anterioridad al ascenso principal de la Cordillera Patagónica. Su predominante composición lutítica sugeriría una facies de relativa profundidad y escasa energía, alejada de la costa, la que se habría ubicado más hacia el oriente. En el tramo inferior, las lutitas llevan intercalaciones areniscosas y concreciones con fósiles, en su mayoría gasterópodos y bivalvos, además de unos pocos braquiópodos y equinodermos. En general, esta fauna participa de las características de otras eocenas del occidente patagónico, presentes en formaciones con las que se correlacionaría la Formación Río Foyel (Fig. 3). Especies comunes son Loxocardium puelchum (Sowerby), Venericardia (Venericor) sp. y Panopea nucleus (Ihering). Fusinus patagoniensis sp. nov. y Panopea zinmeisteri sp. nov. tienen mucha similitud con formas del Eoceno Antártico.

Entre las especies mencionadas por otros autores para la Formación Río Foyel, se destaca Iheringiella patagonensis (Desor) por ser frecuente y característica de los "Estratos con Monophoraster y Venericor", eocenos, que afloran a lo largo del borde oriental patagónico (Camacho, 1974).

La ausencia de ostreidos, briozoos y corales es llamativa, tratándose de organismos relativamente frecuentes en formaciones vecinas contemporáneas, aunque más litorales. Las siguientes especies de moluscos son nuevas: Fusinus patagoniensis, Neilo biradiata y Panopea zinsmeisteri.

El tramo superior contiene foraminíferos, ostrácodos y microfloras indicadoras de una edad entre Eoceno tardío y Oligoceno temprano a medio.

\section{AGRADECIMIENTO}

Los autores agradecen a la Prof. Mónica Longobucco su colaboración en la preparación de este trabajo.

\section{BIBLIOGRAFÍA}

Adams, A. 1852. Descriptions of a new genus, and of several new species, of Mollusca, from the Cumingian collection. Proceedings of the Zoological Society of London, Part. 20, 92-95.

Adams, A. 1854. Descriptions of new shells, from the Cumingian collection. Proceedings of the Zoological Society of London, 20, 90-92.

Adams, H. and Adams, A. 1853-1858. The genera of Recent Mollusca arranged according to their organization. 1 (1853-54), 1-484; 2 (1854-58), 1-661; 3 (1858), 1-136.

Agassiz, L. 1836. Prodrome d'une monographie des radiaires ou échinodermes. Mémoire de la Société Naturelle de Neuchâtel, 1, 168-199.

Ameghino, F. 1906. Les formations sédimentaires du Crétacé supérieur et du Tertiare de Patagonie. Anales Museo Nacional de Buenos Aires, 15 (serie 3, tomo 8), $1-568$.

Archangelsky, C. 1968. Sobre microplancton del Terciario inferior de Río Turbio, Provincia de Santa Cruz. Ameghiniana, 5, 406-416.

Bertels, A. 1970. Sobre el "Piso Patagoniano" y la representación de la época del Oligoceno en Patagonia Austral, República Argentina. Revista de la Asociación Geológica Argentina, 25, 455-501.

Bertels, A. 1980. Foraminíferos (Protozoa) y ostrácodos (Arthropoda) de las "Lutitas de Río Foyel" (Oligoceno) 
de la Cuenca de Nirihuau, Provincia de Río Negro, República Argentina. Ameghiniana, 17, 49-52.

Bertels, A. 1993. Foraminíferos bentónicos (Protozoa) de las "Lutitas de Río Foyel" (Oligoceno medio bajo), Provincia de Río Negro, República Argentina. Revista Española de Micropaleontología, 25 (3), 23-58.

Bertels, A. 1994a. Los foraminíferos planctónicos (Protozoa) de las "Lutitas de Río Foyel" (Oligoceno medio bajo), Cuenca Ñirihuau-Ñorquinco-Cushamen, Provincia de Río Negro, Argentina. Ameghiniana, 31, 187-194.

Bertels, A. 1994b. Foraminíferos (Protozoa) y paleoambientes de las "Lutitas de río Foyel" (Oligoceno medio bajo), Cuenca de Nirihuau-Ñorquinco-Cushamen, Provincia de Río Negro, República Argentina. Revista Española de Micropaleontología, 26 (2), 99-108.

Beurlen, K. 1944. Beiträge zur Stammesgeschichte des Muscheln. Sitzungsberichte des mathematischnaturwinenschaftlichen. Abteilung der Bayerischen Akademi des Wissenschaften zur München, 1-2, 1-133.

Born, I. 1778. Index rerum naturalium. Musei Caesarei Vindobonensis, Pars 1 Testacea. Vindobonae, 1-458.

Broderip, W.J. 1833. Descriptions of some new species of Cuvier's Family of Brachiopoda. Proceedings of the Zoological Society of London, Part. 1, 1-126.

Bruguière, J.B. 1789. Encyclopédie Méthodique; histoire naturelle des vers. 1, París, 1-344.

Bruguière, J.B. 1791. Tableau encyclopédique et méthodique des trois regnes de la Nature, 7. Helminthologie, 1791.

Camacho, H.H. 1967. Las transgresiones del Cretácico superior y Terciario de la Argentina. Revista de la Asociación Geológica Argentina, 22 (4), 253-280.

Camacho, H.H. 1974. Bioestratigrafía de las formaciones marinas del Eoceno y Oligoceno de la Patagonia. Anales de la Academia Nacional de Ciencias Exactas, Físicas y Naturales 26, 39-57.

Camacho, H.H., Chiesa, J.O. y Parma, S.G. 1998. Relaciones estratigráficas entre formaciones terciarias en el occidente de la Provincia de Santa Cruz. Revista de la Asociación Geológica Argentina, 53 (2), 273-281.

Camacho, H.H., Chiesa, J.O., Parma, S.G. y del Río, C.J. 2000a. Invertebrados marinos eocenos de los cerros Palique y Castillo, sudoeste de la provincia de Santa Cruz, Argentina. Ameghiniana, 37, 58-72.

Camacho, H.H., Chiesa, J.O., Parma, S.G. y Reichler, V. 2000b. Invertebrados marinos de la Formación Man Aike (Eoceno medio), Provincia de Santa Cruz, Argentina. Boletín de la Academia Nacional de Ciencias, Córdoba, 64, 187-208.

Carcelles, A. 1953. Nuevas especies de gasterópodos del Uruguay y Argentina. Comunicaciones Zoológicas del Museo de Historia Natural de Montevideo, 4 (70), 1-16.

Cazau, L. 1972. La Cuenca del Ñirihuau-ÑorquincoCushamen. In: Geología Regional Argentina (Editor A.F. Leanza). Córdoba, 732-734.

Cazau, L.B. 1980. Cuenca de Ñirihuau-ÑorquincoCushamen. Segundo Simposio de Geología Regional Argentina, 2, 1149-1172. Academia Nacional de Ciencias, Córdoba.

Chiesa, J.O. y Camacho, H.H. 1995. Bioestratigrafía del
Paleógeno marino en el noroeste de la provincia de Santa Cruz, Argentina. Monografias de la Academia Nacional de Ciencias Exactas, Físicas y Naturales (Buenos Aires), 11, 9-15.

Chiesa, J.O., Parma, S.G. y Camacho, H.H. 1995. Invertebrados marinos de la Formación El Chacay (Eoceno), provincia de Santa Cruz, Argentina. Sistemática y Bioestratigrafía. Monografías de la Academia Nacional de Ciencias Exactas, Físicas y Naturales (Buenos Aires), 11, 17-68.

Children, J.G. 1822-1824. Lamarck's genera of the shells translated from the French, with plates from original drawings by Miss Anna Children. Quaterly Journal of Science, 14, 64-68 (1822); 14, 298-322 (1823); 15, 216258 (1823); 16, 49-79 (1823); 16, 241-264 (1824) [Ver A.S. Kennard, A.E. Salisbury and B.B. Woodward. 1931. The types of Lamarck's genera of shells as selected by J.G. Children in 1823. Smithsonian Miscellaneous Collection, 82 (17), 1-40].

Claus, C.F.W. 1876-1880. Grunzuge der Zoologie. $3^{\text {rd }}$ Ed. 1254 pp. (1876). $4^{\text {th }}$ Ed., 2, 522 pp., (1880), Marburg and Leipzig.

Cossmann, A.E.M. 1886. Catalogue des coquilles fossiles de l'éocène des environs de Paris. Annales de la Societé Royale de Malacologie de Belgique, 21, 17-186.

Cuvier, G. 1797. Tableau élémentaire de l'Histoire Naturelle des Animaux. París, 1-70.

Da Costa, E.M. 1778. Historia Naturalis Testaceorum Britanniae, or the British Conchology, containing the descriptions and others particulars of natural history of the shells of Great Britain and Ireland. London, 254 pp.

Dall, W.H. 1889. A preliminary catalogue of the shellbearing marine mollusks and brachiopods of the southeastern coast of the United States. Bulletin of the $U$. S. National Museum, 37, 1-212.

Dall, W.H. 1895. Contributions to the Tertiary Fauna of Florida. Transactions Wagner Free Institute Science. Philadelphia, Part. 3: A new classification of the Pelecypoda, 485-570.

Deshayes, G.P. 1858. Descriptions des Animaux sans vertebres decouverts dans le bassin de Paris pour servir de supplément à la description des coquilles fossiles des environs de Paris, comprenant une revue générale de toutes les espèces actuellement connues. Paris, 1, 393704.

Desor, E. 1847. Sur quelques oursins fossiles de la Patagonie. Bulletin de la Société Geologique de France, $2^{\circ}$ Ser. 4, 287-288.

D’Orbigny, A. 1847. Paleontologie Francaise: Description des Animaux Invertebrés Terrain Crétacé, 4, 390 pp.

Duméril, A.M.C. 1806. Zoologie analytique ou méthode naturelle de classification des animaux. París, 344 pp.

Echevarría, A. 1981. Informe Hoja 41 a. Servicio Geológico Nacional (inédito).

Erdmann, S. y Morra, G.A. 1985. Nuevos moluscos de la Formación San Julián, Provincia de Santa Cruz. Ameghiniana, 22, 289-295.

Feldmann, R.M., Casadío, S., Aguirre Urreta, M.B. and Foland, K.A. 1997. Radiometric age and Biotic affinities of Decapoda Crustaceans from the Centinela Formation, 
Southern Argentina. Abstracts for 1997. Geological Society of America, Annual Meeting $\mathrm{n}^{\circ}$ 17, p. 427. Washington D.C.

Feruglio, E. 1927. Estudio geológico de la región pre y subandina en la latitud del Nahuel Huapi. Anales de la Sociedad Argentina de Estudios Geográficos "Gaea", 2 (3), 425-437.

Feruglio, E.. 1936. Nuevas especies de moluscos supracretácicos y terciarios de la Patagonia. Boletín de Informaciones Petroleras (Buenos Aires), 139, 121-136.

Feruglio, E. 1941. Nota preliminar sobre la Hoja Geológica "San Carlos de Bariloche" (Patagonia). Boletín de Informaciones Petroleras, 18, $\mathrm{n}^{\circ}$ 200, 52.

Feruglio, E. 1949. Descripción Geológica de la Patagonia 2, p. 131 y p. 134.

Férussac, A.E. de. 1822. Tableaux systématiques des animaux mollusques. Paris, London, $110 \mathrm{pp}$.

Finlay, H.J. 1930. Additions to the Recent molluscan faunas of New Zealand, 3. Transactions of the New Zealand Institute, 61, 222-247.

Fischer, P. 1880-1887. Manuel de Conchyliologie et de paleontologie conchyliologique, ou histoire naturelle des mollusques vivants et fossils. Paris, fasc. 1 (1880), 2 (1881), 3 (1881), 4 (1882), 5 (1883), 6 (1883), 7 (1884), 8 (1885), 9 (1885), 10 (1886), 11 (1887).

Fleming, J. 1820. Conchology. D. Brewster's Encyclopaedia, 12, Edinburgh, 55-107.

Fleming, J. 1828. A history of British animals, exhibiting the descriptive characters and systematical arrangement of the genera and species of quadrupeds, birds, reptiles, fishes, Mollusca and Radiata of the United Kingdom; including the indigenous, extirpated, and extinct kinds; together with periodical and occasional visitants. Edinburgh. 554 pp.

Forbes, E. 1838. Malacologia Monensis. A Catalogue of the Mollusca Inhabiting the Isla of Man and the Neighbouring sea. Edinburg, 63 pp.

Franchi, M.R., Nullo, F.E., Sepúlveda, E.G. y Uliana, M.A. 1984. Las sedimentitas terciarias. IX $X^{\circ}$ Congreso Geológico Argentino (San Carlos de Bariloche), Relatorio 1 (9), 215-266.

Frassinetti, D. y Covacevich, V. 1999. Invertebrados fósiles marinos de la Formación Guadal (Oligoceno superiorMioceno inferior) en Pampa Castillo, Región de Aisén, Chile. Subdirección Nacional de Geología, Boletín $\mathrm{n}^{\circ} \mathbf{5 1}$, Santiago, Chile, 96 pp.

Furque, G. y Camacho, H.H. 1972. El Cretácico superior y Terciario de la región austral del lago Argentino (Provincia de Santa Cruz). Cuartas Jornadas Geológicas Argentinas (Mendoza, 1969), Actas, 3, 61-76.

Gmelin, J.F. 1791. Caroli Linné systema naturae per regnatria naturae. Editio decima tertia, 1, parte 6, 30213910 .

González Bonorino, F. 1944. Descripción geológica y petrográfica de la Hoja 41b "Río Foyel" (Terr. Río Negro). Boletín de la Dirección de Minas, Geología e Hidrología, $\mathrm{n}^{\circ}$ 56, 19-21.

Grabau, A.W. 1904. Phylogeny of Fusus and its allies. Smithsonian Miscelanious Collection, 44, 1-157.

Gray, J.E. 1824. Supplements of the appendix of Captain
Parry's Voyage for the discovery of a North-West Passage, in the years 1819-20 containing an account of the subjects of Natural History Shells. London, 220-246.

Gray, J.E. 1853. A revision of the genera of some families of Conchyfera, or bivalve shells. The Annals and Magazine of Natural History Series, 2 (11), 33-44.

Gray, J.E. 1855. Catalogue of the Recent Echinida, or sea eggs, in the collection of the British Museum. Part. IEchinida Irregularia. British Museum, London, 1-69.

Griffin, M. 1991. Eocene bivalves from the Rio Turbio Formation, Southwestern Patagonia (Argentina). Journal of Paleontology, 65, 104-175.

Groeber, P. 1939. El Eógeno del Neuquén, el piso de Navidad chileno, la formación de Río Grande y sus relaciones. Anales del Museo Argentino de Ciencias Naturales "Bernardino Rivadavia", 40, 49-94. Buenos Aires.

Groeber, P. 1954. La Serie "Andesítica" patagónica. Sus relaciones, posición y edad. Revista Sociedad Geológica Argentina, 9 (1), 39-42.

Ihering, H. von. 1897. Os molluscos dos terrenos terciarios de Patagonia. Revista do Museu Paulista, 2, 217-382.

Ihering, H. von. 1899. Die Conchylien der Patagonischen Formation. Neue Jahrbuch fur Mineralogie, Geologie und Paleontologie, 2, 1-46.

Ihering, H. von. 1903. Les Brachiopodes Tertiaires de Patagonie. Anales Museo Nacional de Buenos Aires, 9 (serie 3, tomo 2), 321-349.

Ihering, H. von. 1904. Nuevas observaciones sobre moluscos cretáceos y terciarios de Patagonia. Revista del Museo de La Plata, 11, 229-243.

Ihering, H. von. 1907. Les Mollusques fossiles du Tertiaire et du Crétacé supérieur de l'Argentine. Anales Museo Nacional de Buenos Aires, 15 (serie 3, tomo 7), 1-611.

Ihering, H. von. 1914. Catálogo de molluscos cretáceos e terciarios de Argentina de colleccao do Autor. Revista Museu Paulista, 1 (3), p. 9, p. 33, p. 64, p. 100.

Keen, A.M. 1936. A new pelecypod genus of the family Cardiidae. Transactions of the San Diego Society of Natural History, 8 (17), 119-120.

King, W. 1850. Monograph of the Permian Fossils of England. Palaeontographical Society Monograph, 3, 258 pp.

Korobkov, I.A. 1954. Handbook, and systematic guide to the Tertiary Mollusca. Lamellibranchia. State Scientific and Technical Publishing Agency Oil and Mineral Fuel Literature, Leningrado, 444 pp. (en ruso).

Lamarck, J.P.B.A. de. 1799. Prodrome d'une nouvelle classification des coquilles, comprenant une rédaction apropriée des caractères géneriques et l'etablissement d'un grand nombre de genres nouveaux. Memoire de la Société d'Histoire Naturelle, 1, 90 pp.

Lamarck, J.P.B.A. de. 1801. Système des animaux sans vertébres ou tableau général des classes, des orders et des genres de ces animaux, 8, $432 \mathrm{pp}$.

Lamarck, J.P.B.A. de. 1805. Mémoires sur les fossiles des environs de Paris, comprennant la determination des espèces qui appartiennent aux animaux marines sans vertèbres, et dont la plupart son figurés dans la collection des vélins du Muséum. Annales du Muséum National 
d'Histoire Naturelle de Paris 6, 117-126; 214-228; 337 345; 407-415.

Lamarck, J.P.B.A. de. 1809. Philosophie Zoologique ou exposition des considerátions relatives à l'histoire naturelle des animaux, la diversité de leur organisation et des faculltés qu'ils on obtiennent, aux causes physiques qui maintiennent en eux la vie, et donnent lieu au mouvements qu'ils exécutent; enfin, à celles qui produisent les unes les sentiments, et les autres l'intelligence de ceux qui en sont donés. 1, 1-422; 2, 1473.

Lamarck, J.P.B.A. de. 1819. Histoire naturelle des animaux sans Vertèbres. 6 (1), 1-343.

Lambert, J. 1905. Echinides du sud de la Tunisie (environs de Tatahouine). Bulletin de la Société Géologique de France, 4 (5), 569-577.

Leach, W.E. 1819. A list of invertebrate animals discovered by H. M. S. Ship Isabella, in a Voyage to the arctic regions. Appendix II, 61-64 in Ross, C.J. Voyage of Discovery Baffin's Bay. Appendix 1, 1-252.

Leske, N.G.. 1778. Klein's Naturalis dispositio echinodermatum. Leipzig, 278 pp.

Linnaeus, C. 1758. Systema Naturae per regnatria naturae, secundum classes, ordenes, genera, species. 1, Editio 10 reformada, Estocolmo, $824 \mathrm{pp}$.

Malumián, N. 1990. Foraminíferos de la Formación Man Aike (Eoceno sureste Lago Cardiel, Provincia de Santa Cruz). Revista de la Asociación Geológica Argentina, 45, 364-385.

Malumián, N., Camacho, H.H. y Gorroño, R. 1978. Moluscos del Terciario Inferior (Magallaniense) de la Isla Grande de Tierra del Fuego (República Argentina). Ameghiniana, 15, 265-284.

Malumián, N., Echevarría, A., Martínez Macchiavello, J.C. y Nañez, C. 1984. Los Microfósiles. IX ${ }^{\circ}$ Congreso Geológico Argentino (San Carlos de Bariloche), Relatorio, 2, 485-526.

Martínez Pardo, R. 1968. Zonación preliminar del Terciario de Chile Central mediante foraminíferos planctónicos y su correlación regional y transcontinental. In: El Terciario de Chile Zona Central (Coord. G. Cecioni). Sociedad Geológica de Chile, Santiago, Chile, 191-203.

Melchor, R., Casadío, S. y Visconti, G. 1992. Análisis estratigráfico secuencial de los depósitos lacustres eocenos de la Formación Vaca Mahuida, SO de la Provincia de La Pampa, Argentina. Cuarta Reunión Argentina de Sedimentología (La Plata), Actas, 1, 151158.

Menard de la Groye, F.J.B. 1807. Mémoir sur un nouveau genre de coquille de la famille des Solenoides. Annales du Muséum d'Histoire Naturelles de Paris, 9, 131-139.

Montfort, P.D. 1810. Conchyliologie systématique et classification méthodique des coquilles, 2, $676 \mathrm{pp}$.

Morra, G.A. 1985. Revisión de Zygochlamys (Mollusca: Bivalvia). Ameghiniana, 22, 300-308.

Neumayr, N. 1884. Zur Morphologie des Bivalvenschosses. Sitzungberichte der Akademie der Wissenschaften zu Wien, 88 (1), 385-419.

Newell, N.D. 1965. Classification of the Bivalvia. American Museum Novitates, $\mathbf{n}^{\mathbf{0}} \mathbf{2 2 0 6}, 25$ pp.
Newton, R.B. 1922. Eocene Mollusca from Nigeria. Bulletin of the Geological Survey of Nigeria, 3, $136 \mathrm{pp}$.

Niemeyer, H. 1975. Geología de la región comprendida entre el lago General Carrera y el río Chacabuco. Provincia de Aisén, Chile. Memoria de Título, Universidad de Chile, Departamento de Geología, 309 pp. (inédita).

Niemeyer, H., Skarmeta, J., Fuenzalida, R. y Espinosa, W. 1984. Hojas Península de Taitao y Puerto Aisén, Región de Aisén del General Carlos Ibáñez del Campo. Servicio Nacional de Geología y Minería, Carta Geológica de Chile, $\mathbf{n}^{\mathbf{0}} \mathbf{6 0 - 6 1}, 80 \mathrm{pp}$.

Ortmann, A.E. 1899. The fauna of the Magellanian beds of Punta Arenas, Chile. The American Journal of Science, 8, 427-432.

Ortmann, A.E. 1902. Tertiary Invertebrates. Reports of the Princeton Expedition to Patagonia, 4 (2), Princeton, New York, 45-332.

Petersen, C. y González Bonorino, F. 1947. Observaciones geológicas en el Chubut occidental. Revista de la Sociedad Geológica Argentina, 2, 177-222.

Philippi, R.A. 1845-1851. Abbildungen und Beschreibungen neuer oder wenig gekannter Conchylien, 1, 1845, 204 pp.; 2, 1847, 231 pp.; 3, 1851, 138 pp. Kassel.

Philippi, R.A. 1887. Los fósiles terciarios y cuartarios de Chile. Santiago, Chile, 256 pp.

Pöthe de Baldis, E.D. 1984. Microfloras cenozoicas. $I X^{\circ}$ Congreso Geológico Argentino (San Carlos de Bariloche), Relatorio, 2 (4), 393-411.

Rafinesque, C.S. 1815. Analyse de la Nature, ou Tableau de l'Universe et des corps organisées. Palermo, 224 pp.

Ramos, V.A. 1982. Las ingresiones pacíficas del Terciario en el norte de la Patagonia (Argentina). $I I I^{\circ}$ Congreso Geológico Chileno, Santiago, Chile, A263-A288.

Rassmuss, J. 1922. Apuntes geológicos sobre los hallazgos de carbón al sur del lago Nahuel Huapi. Boletín de la Dirección General de Minas y Geología, 28B, p. 10.

Riggi, J.C. 1957. Resumen geológico de la zona de los lagos Pueyrredón y Posadas, Provincia de Santa Cruz. Revista de la Asociación Geológica Argentina, 12 (2), 65-97.

Röding, P.F. 1798. Museum Boltenianum sive Catalogus cimeliorum e tribus regnis naturae quae olim Collegerat Joa. Fried. Bolten. M.D.p.d., Pars Secunda. Typis Johan Christi Trapii. Hamburg, 199 pp.

Rossi de García, E. y Levy, R. 1984. Megafaunas de invertebrados. IX ${ }^{o}$ Congreso Geológico Argentino (San Carlos de Bariloche), Relatorio, 2, 467-484.

Roth, S. 1908. Beitrag zur gliederung der Sedimentalablagerungen in Patagonien und der Pampas region. Neues Jahrbuch für Mineralogie, Geologie und Palaeontologie, 27, 92-150.

Roth, S. 1922. Investigaciones geológicas en la región norte de la Patagonia durante los años 1897-1899. Revista Museo de La Plata, 26, p. 347.

Schmidt, C.F. 1818. Versuch über die beste Einrichtung zur Aufstellung, Behandlung und Aufbewahrung der verschiedenen Naturkörper und Gegenstände der Kunst, vorzüglich der Conchylien-sammlungen; nebst Kurzer Beurtheilung der conchyliologische Systeme, p. 57, p. 176. 
Shaw, E. 1939. Informe Geológico "Zona Hoja 41-b (Ñorquinco), Terr. Río Negro”, n 139, 6 pp. Yacimientos Petrolíferos Fiscales (inédito), Buenos Aires.

Sowerby, G.B. 1846 (1876). Descriptions of Tertiary fossil shells from South America. In: Ch. Darwin, Geological observations on the Volcanic islands and parts of South America. London, 605-623.

Spalletti, L.A. 1984. Paleogeografía de la Formación Nirihuau y sus equivalentes en la región occidental de Neuquén, Río Negro y Chubut. Revista de la Asociación Geológica Argentina, 38, 454-468.

Steinmann, G. und Wilckens, O. 1908. Kreide und Tertiärfossilien aus den Magellansländern, gesammelt von der Schwedischen Expedition 1895-1897. Arkiv für Zoologi, Stockholm, 4, 1-119.

Stewart, R.B. 1930. Gabb's California Cretaceous and Tertiary type Lamellibranchs. Academy of Natural Sciences of Philadelphia, Special Publication, 3, 1-314.

Stilwell, J.D. and Zinsmeister, W.J. 1992. Molluscan Systematics and Biostratigraphy Lower Tertiary La Meseta Formation, Seymour Island, Antarctic Peninsula. American Geographical Union, Washington DC, 55, Antarctic Research Series, 192 pp.

Stoliczka, F. 1870-1871. Cretaceous fauna of Southern India. 3, The Pelecypoda with a review of all known genera of this class, fossil and recent. Memoir of the Geological Survey of India, Palaeontologia Indica, $6^{\text {th }}$ series, $535 \mathrm{pp}$.

Swainson, W. 1840. A Treatise on Malacology or shells and shell-fish. The Cabinet Cyclopedia, Natural History. London, $420 \mathrm{pp}$.

Tavera, J.J. 1942. Contribución al estudio de la estratigrafía y paleontología del Terciario de Arauco. Anales del $1^{o}$ Congreso Panamericano de Ingenieros de Minas y Geología, 2, Santiago, Chile, 581-632.
Thiele, J. 1925. Gastropoda der deutschen TiefseeExpedition, 2. Wissentschaftichen Ergebnisse deutsche Tiefsee expedition "Valdivia" 17, 37-382.

Ubaldón, M.C. 1981. Informe sobre el contenido paleontológico de la Hoja $41^{a}$ "El Bolsón". Servicio Geológico Nacional, G 1115, 1-3 (inédito).

Ugarte, F. 1956. El Grupo de Río Zeballos en el flanco occidental de la Meseta Buenos Aires (Provincia de Santa Cruz). Revista de la Asociación Geológica Argentina, 11 (3), 202-216.

Uliana, M.A. 1974. Geología superficial de la parte E de la Cuenca Neuquina. Informe de Yacimientos Petrolíferos Fiscales, (inédito). Buenos Aires.

Waagen, W.H. 1883. Salt Range Fossils, part. 4 (2) Brachiopoda. Palaeontologia Indica, Memoir, series, 13 (3), 547-610.

Wenz, W. 1938-1944. Gastropoda. Teil I. Allgemeiner Teil/Prosobranchia. Handbuch der Paläozoologie, Band 6. Berlín, 1639 pp.

Wilckens, O. 1910. Die Anneliden, Bivalven, und Gastropoden der Antarktischen Kreide-formation. Wissenschaften Ergebnissen Schwedische SudpolarExpedition 1901-1903, 3 (12), 1-132.

Wilckens, O. 1911. Die Mollusken der Antarktischen Tertiärformation. Wissenschaften Ergebnissen Schwedische Sudpolar-Expedition 1901-1903, 3, (13), 142.

Windhausen, A. 1931. Geología Argentina. 2, 368 pp.

Woodward, S.P. 1851. A Manual of the Mollusca, part 1, London, $158 \mathrm{pp}$.

Zinsmeister, W.J. 1984. Late Eocene bivalves from the La Meseta Formation collected during the 1974-1975 joint Argentine-American expedition to Seymour Island, Antarctic Peninsula. Journal of Paleontology, 58, 1497 1527.

Manuscrito recibido: 29 de diciembre, 2000 Manuscrito aceptado: 13 de junio, 2001 